\title{
Biphasic activation of nuclear factor- $\kappa B$ and expression of p65 and c-Rel following traumatic neuronal injury
}

\author{
HUASHENG ZHANG ${ }^{1}$, DINGDING ZHANG ${ }^{1}$, HUA LI $^{1}$, HUIYING YAN $^{1}$, ZIHUAN ZHANG $^{2}$, \\ CHENHUI ZHOU ${ }^{1}$, QIANG $\mathrm{CHEN}^{3}$, ZHENNAN $\mathrm{YE}^{3}$ and CHUNHUA HANG ${ }^{1,3}$ \\ ${ }^{1}$ Department of Neurosurgery, Jinling Hospital, School of Medicine, Nanjing University, Nanjing, Jiangsu 210002; \\ ${ }^{2}$ Department of Neurosurgery, Zhongdu Hospital, Bengbu, Anhui 233004; ${ }^{3}$ Department of Neurosurgery, \\ Southern Medical University (Guangzhou), Jinling Hospital, Nanjing, Jiangsu 210002, P.R. China
}

Received February 15, 2016; Accepted February 22, 2018

DOI: 10.3892/ijmm.2018.3567

\begin{abstract}
The transcription factor nuclear factor $-\kappa \mathrm{B}(\mathrm{NF}-\kappa \mathrm{B})$ has been shown to function as a key regulator of cell death or survival in neuronal cells. Previous studies indicate that the biphasic activation of $\mathrm{NF}-\kappa \mathrm{B}$ occurs following experimental neonatal hypoxia-ischemia and subarachnoid hemorrhage. However, the comprehensive understanding of NF- $\mathrm{KB}$ activity following traumatic brain injury (TBI) is incomplete. In the current study, an in vitro model of TBI was designed to investigate the NF- $\kappa$ B activity and expression of p65 and c-Rel subunits following traumatic neuronal injury. Primary cultured neurons were assigned to control and transected groups. NF- $\mathrm{BB}$ activity was detected by electrophoretic mobility shift assay. Western blotting and immunofluorescence were used to investigate the expression and distribution of p65 and c-Rel. Reverse transcription-quantitative polymerase chain reaction was performed to assess the downstream genes of NF- $\mathrm{NB}$. Lactate dehydrogenase (LDH) quantification and trypan blue staining were used to estimate the neuronal injury. Double peaks of elevated NF- $\mathrm{BB}$ activity were observed at 1 and $24 \mathrm{~h}$ following transection. The expression levels of downstream genes exhibited similar changes. The protein levels of p65 also presented double peaks while c-Rel was elevated significantly in the late stage. The results of the trypan blue staining and LDH leakage assays indicated there was no sustained neuronal injury during the late peak of $N F-\kappa B$ activity. In conclusion, biphasic activation of $N F-\kappa B$
\end{abstract}

Correspondence to: Professor Chunhua Hang, Department of Neurosurgery, Jinling Hospital, School of Medicine, Nanjing University, 305 East Zhongshan Road, Nanjing, Jiangsu 210002, P.R. China

E-mail: hang_neurosurgery@163.com

Abbreviations: NF- $\kappa \mathrm{B}$, nuclear factor- $\kappa \mathrm{B}$; TBI, traumatic brain injury; EMSA, electrophoresis mobility shift assay

Key words: inflammatory response, nuclear factor- $\mathrm{\kappa} \mathrm{B}$, traumatic neuronal injury, biphasic activation is induced following experimental traumatic neuronal injury. The elevation of p65 and c-Rel levels at different time periods suggests that within a single neuron, $N F-\kappa B$ may participate in different pathophysiological processes.

\section{Introduction}

Traumatic brain injury (TBI) accounts for $15 \%$ of body trauma worldwide and usually leads to neurological dysfunction or mortality (1). Although great efforts have been made to investigate the damage mechanism of TBI, this highly complex disorder is not completely understood. Neuronal injury following TBI can be classified into primary and secondary damage; the latter is induced following the primary injury and may persist for a prolonged time due to adverse biochemical changes (2). Several signaling cascades mediate secondary neuronal injury, including oxidative stress, overload of intracellular calcium, cytoskeletal and mitochondrial dysfunction, and inflammatory cell infiltration (3). In particular, a sterile inflammatory response induced by various inflammatory mediators has been suggested to serve a key role in secondary brain injury (4).

The nuclear factor- $\kappa \mathrm{B}(\mathrm{NF}-\kappa \mathrm{B}) /$ Rel proteins are a family of transcription factors including five members, namely p50, p52, p65/RelA, RelB and c-Rel, which are able to form homo- or heterodimers with the ability to transmit receptor signals to the nucleus (5). As a key factor in the inflammatory response, $\mathrm{NF}-\kappa \mathrm{B}$ regulates a number of genes, including apoptotic mediators, growth factors, inflammatory cytokines, adhesion molecules and enzymes, all of which are involved in crucial cellular pathophysiology processes (6-9). Previous studies have shown that NF- $\kappa \mathrm{B}$ contributes to neuronal injury by inducing proinflammatory cytokines, but conversely also promotes cell survival through upregulating the expression of anti-apoptotic mediators such as B-cell lymphoma 2 (Bcl-2) and Bcl-extra large (10). This reciprocal interaction between pro- and anti-apoptotic pathways indicates that NF- $\kappa \mathrm{B}$ serves a dual role in the regulation of neuronal survival in pathological conditions, with positive and negative effects on brain damage and neuroprotection (11-15).

Previous studies have demonstrated that double peaks of cerebral NF- $\kappa \mathrm{B}$ activity occur following experimental neonatal 
hypoxia-ischemia and subarachnoid hemorrhage $(16,17)$. However, the full details of $\mathrm{NF}-\kappa \mathrm{B}$ activation following TBI remain obscure. Thus, the present in vitro study was designed with the aim of investigating the activation time course of $\mathrm{NF}-\kappa \mathrm{B}$ and the expression of p65 and c-Rel subunits in primary cultured cortical neurons following transection injury.

\section{Materials and methods}

Primary culture of cortical neurons. A primary cortical neuron culture was prepared using an established technique with certain modifications (18). Embryos from wild-type female mice of the strain BALB/c were used in the study. In brief, cerebral cortices were removed from the embryos at 15-17 days, stripped of meninges and blood vessels and minced with $\mathrm{Ca}^{2+} / \mathrm{Mg}^{2+}$-free Hank's balanced saline solution (cat. no. 14170112; Thermo Fisher Scientific, Inc., Waltham, MA, USA) with the aid of a dissection microscope. The cortex was dissected free and treated with $0.125 \%$ trypsin for $5 \mathrm{~min}$ at $37^{\circ} \mathrm{C}$. The trypsin-containing supernatant was then discarded. Subsequently, the tissues were washed three times with precooled phosphate-buffered saline (PBS), and then triturated in PBS with fire-polished glass pipettes. The neuron suspension was filtered through a $22-\mu \mathrm{m}$ filter into a $15-\mathrm{ml}$ polypropylene conical tube, and centrifuged at $1,500 \mathrm{x}$ for $5 \mathrm{~min}$ at $4^{\circ} \mathrm{C}$. The sediment was resuspended in neurobasal medium (cat.no. 21103-049) with B27 (cat. no. 10889-038) (both from Thermo Fisher Scientific, Inc.), $100 \mathrm{U} / \mathrm{ml}$ penicillin and $0.1 \mathrm{mg} / \mathrm{ml}$ streptomycin. Finally, the neurons were plated onto poly-D-lysine-coated 6-well plates at a density of $1 \times 10^{6}$ cells/well. The cells were maintained at $37^{\circ} \mathrm{C}$ in a humidified $5 \% \mathrm{CO}_{2}$ atmosphere. Half of the culture medium was replaced with fresh medium every 3 days. All experiments were performed following 10-12 days in vitro. Ethical approval for use of the embryonic tissue was given by the Medical Ethics Committee of Jinling Hospital (Nanjing, China) with the following reference number: SYXK 2012-0047. All surgical procedures were performed in accordance with guidelines of the Jinling Animal Care and Use Committee.

Traumatic neuronal injury model. A transection model was performed as described previously (19). This transection model used a slender plastic needle to scrape adherent cells from a culture dish, which tore the soma while leaving a large proportion of cells intact (20). Briefly, each well of a 6-well plate was manually scratched with a sterile plastic needle in the pattern of a 9x9-square grid with 4-mm spacing between the lines. Cell cultures were then placed in an incubator at $37^{\circ} \mathrm{C}$ until a designated post-trauma time point was reached. After 1, 6, 12, 24, 36 and $48 \mathrm{~h}$, the neurons were collected for analysis using an electrophoretic mobility shift assay (EMSA), western blotting, reverse transcription-quantitative polymerase chain reaction (RT-qPCR), typan blue staining and lactate dehydrogenase (LDH) release assay. Since a scratch injury initially activates neurons at the wound edge and later expands to the entire neuron monolayer, the entire culture on each dish was used for all experiments.

Cell nuclear protein extraction. Proteins from the nucleus and cytoplasm of the cells were extracted according to the methods described in previous studies $(21,22)$. The primary cultured neurons were washed twice with PBS and scraped in cold PBS. The clustered neurons were then resuspended with $200 \mu \mathrm{l}$ ice-cold buffer $\mathrm{A}$, which is composed of $10 \mathrm{mM}$ HEPES (pH 7.9), 2 mM MgCl 2,10 mM KCl, 0.1 mM EDTA, $1 \mathrm{mM}$ dithiothreitol (DTT) and $0.5 \mathrm{mM}$ phenylmethylsulfonyl fluoride (PMSF; all from Sigma-Aldrich; Merck KGaA, Darmstadt, Germany). The homogenate was subsequently incubated on ice for $20 \mathrm{~min}$, and $20 \mu \mathrm{l} 10 \%$ Nonidet P40 solution was added (Sigma-Aldrich; Merck KGaA). The mixture was stirred vortically for $30 \mathrm{sec}$ and spun by centrifugation for $10 \mathrm{~min}$ at $5,000 \mathrm{x} \mathrm{g}, 4^{\circ} \mathrm{C}$. The supernatant comprising cytoplasmic protein was discarded. The precipitated nuclear pellet was resuspended in $40 \mu \mathrm{l}$ buffer $\mathrm{B}$, which comprised $20 \mathrm{mM}$ HEPES (pH 7.9), $420 \mathrm{mM} \mathrm{NaCl}, 1.5 \mathrm{mM} \mathrm{MgCl} 2,0.1 \mathrm{mM}$ EDTA, $1 \mathrm{mM}$ DTT, $0.5 \mathrm{mM}$ PMSF and 25\% (v/v) glycerol. The mixture was incubated on ice for $60 \mathrm{~min}$ with intermittent mixing, and then centrifuged at $13,000 \mathrm{x} \mathrm{g}$ at $4^{\circ} \mathrm{C}$ for $15 \mathrm{~min}$. The supernatant, which contained nuclear proteins, was collected and stored at $-80^{\circ} \mathrm{C}$ for EMSA and western blotting.

EMSA. EMSA was performed using a commercial kit (Gel Shift assay system; Promega Biotech Co., Ltd., Beijing, China) to detect NF- $\kappa$ B DNA binding activity. Double-stranded consensus oligonucleotide probe (5'-AGT TGA GGG GAC TTT CCC AGG C-3') was end-labeled with $\left[\gamma^{-32} \mathrm{P}\right]$ ATP (Free Biotech, Beijing, China) and T4 polynucleotide kinase. Neuron nuclear protein $(2 \mu \mathrm{g}$ in $7 \mu \mathrm{l})$ was incubated at room temperature for $10 \mathrm{~min}$ with $2 \mu \mathrm{l}$ gel shift binding $5 \mathrm{X}$ buffer. The mixture was then incubated for $20 \mathrm{~min}$ with $1 \mu \mathrm{l}^{32} \mathrm{P}$-labeled oligonucleotide probe. Subsequently, the reaction was stopped by adding $1 \mu \mathrm{l}$ gel loading buffer and the mixture was resolved on a native $4 \%$ polyacrylamide gel in $0.5 \mathrm{X}$ Tris-borate-EDTA buffer. Following electrophoresis at $250 \mathrm{~V}$ for $90 \mathrm{~min}$, when the bromophenol blue dye had migrated down three-quarters of the gel, the gel was dried with plastic wrap on a gel dryer prior to exposure to X-ray film (Fuji Hyperfilm; Fujifilms Holdings Corporation, Tokyo, Japan) at $-70^{\circ} \mathrm{C}$. Autoradiography and quantification of the autoradiographic signal were performed by analysis of the X-ray film using Un-Scan-It software (version 7.1; Silk Scientific, Inc., Orem, UT, USA).

Western blotting. The nuclear protein previously stored at $-80^{\circ} \mathrm{C}$ was boiled in loading buffer [containing $1.0 \mathrm{M}$ Tris $\mathrm{HCl}$ (pH 8.5), 8\% (w/v) lithium dodecyl sulfate, $40 \%$ (v/w) glycerol, $2 \mathrm{mM}$ EDTA, $0.5 \mathrm{M}$ DTT and tracking dye in distilled/ deionized water; Beyotime Institute of Biotechnology, Nantong, China] for 5 min. BCA Protein Quantification kit (Beyotime Institute of Biotechnology) was used to measure the protein levels. Then, $45 \mu \mathrm{g}$ protein samples were loaded on a gel for $12 \%$ SDS-PAGE, separated electrophoretically, and then transferred to a polyvinylidene fluoride membrane. Before incubation with antibodies, the membrane was blocked with blocking buffer (cat. no. P0023B; Beyotime Institute of Biotechnology) at $4^{\circ} \mathrm{C}$ overnight. The membrane was incubated in the primary antibody at $4^{\circ} \mathrm{C}$ overnight. The primary antibodies were rabbit anti-rat p65 (sc-372) and c-Rel (sc-272) (1:200 dilution), and rabbit anti-rat histone 3 antibody (sc-8654; 1:200 dilution; each from Santa Cruz Biotechnology, Inc., Dallas, TX, USA) was used as a loading control. After washing three times in TBS containing $0.1 \%$ Tween-20, the horseradish peroxidase-labeled secondary antibody (cat. no. A0208; 
Beyotime Institute of Biotechnology) was applied at a 1:5,000 dilution for $1 \mathrm{~h}$ at room temperature. Afterwards, the blot was washed three times, and the blotted protein bands were visualized by enhanced chemiluminescence (ECL; Amersham; GE Healthcare Life Sciences, Little Chalfont, UK). Relative protein levels were estimated from the mean pixel density using ImageJ software (version 1.51j8; National Institutes of Health, Bethesda, MD, USA), normalized to histone 3, and calculated as target protein expression/histone 3 ratios.

$R T-q P C R$. Total RNA was extracted from fresh neurons with TRIzol reagent (Thermo Fisher Scientific, Inc.) following the manufacturer's protocol and immediately reverse transcribed to cDNA with a PrimeScript RT reagent kit (Takara Biotechnology Co., Ltd., Dalian, China). The primers were synthesized by Invitrogen (Thermo Fisher Scientific, Inc.). The primer sequences were as follows: Interleukin-1 $\beta$ (IL-1 $\beta$ ) forward, GACAGGATGCAGAAGGAGATTACT and reverse, TGATCCACATCTGCTGGAAGGT; tumor necrosis factor- $\alpha$ (TNF- $\alpha$ ) forward, TCTCATTCCTGCTTGTGGC and reverse, CACTTGGTGGTTGCTTACG; caspase-3 forward, GACT GGAAAGCCGAAACTC and reverse, GGCAAGCCATCT CCTCATC; Bcl-2 forward, TGGGATGCTGGAGATGCG and reverse, AGGCTGGAAGGAGAAGATGC; $\beta$-actin forward, AGGCACCAGGGCGTGAT and reverse, CTCAGG CTGGAAGGAGAAGAT. The reactions were conducted in 96 well optical PCR plates using Applied Biosystems StepOnePlus Real-Time PCR system (Thermo Fisher Scientific, Inc.) following the kit protocol. Reactions were performed in a 20- $\mu$ l volume of reaction mix with SYBR Premix Ex Taq (2X) $10 \mu \mathrm{l}$, forward primer $(10 \mu \mathrm{M}) 0.4 \mu \mathrm{l}$, reverse primer $(10 \mu \mathrm{M})$ $0.4 \mu \mathrm{l}$, ROX reference dye (50X) $0.4 \mu \mathrm{l}$, DNA template $2.0 \mu \mathrm{l}$ and $\mathrm{dH}_{2} \mathrm{O} 6.8 \mu \mathrm{l}$ (Takara Biotechnology Co., Ltd.). The thermal cycler protocol comprised: Stage $1,95^{\circ} \mathrm{C}, 30 \mathrm{sec}$ for denaturation; and stage $2,95^{\circ} \mathrm{C}, 5 \mathrm{sec} ; 60^{\circ} \mathrm{C}, 30 \mathrm{sec}$. Stages 1 and 2 were repeated 40 times, alternatingly. The $2^{-\Delta \Delta \mathrm{Cq}}$ method (23) was used for analyzing the data.

Immunofluorescent labeling. For double-immunostaining, cells in 6-well plates were fixed with $4 \%$ formaldehyde for $10 \mathrm{~min}$ at room temperature and then washed three times with PBS. The fixed cells were blocked by treatment with immunostaining blocking buffer (Beyotime Institute of Biotechnology) for $1 \mathrm{~h}$ at room temperature. Subsequently, the cells were incubated overnight at $4^{\circ} \mathrm{C}$ with the primary antibodies: Mouse anti-neuronal nuclei (anti-NeuN; MAB377; 1:200 dilution; EMD Millipore, Billerica, MA, USA), rabbit anti-p65 (sc-372) or anti-c-Rel (sc-272) (1:200; Santa Cruz Biotechnology, Inc.). Goat anti-rabbit IgG (A23220) and goat anti-mouse IgG (A23410) (1:200 dilution; both from Abbkine, Inc., Redlands, CA, USA) were used as secondary antibodies (incubation for $1 \mathrm{~h}$ at room temperature). After washing, neurons were incubated with 4',6-diamidino-2-phenylindole (DAPI) for $5 \mathrm{~min}$ at room temperature to stain the cell nuclei. Fluorescence microscopy imaging was performed using a ZEISS HB050 inverted microscope system (Zeiss AG, Oberkochen, Germany).

Cell viability analysis. Primary cultured neuron viability was quantified by measuring the release of the cytosolic enzyme,
LDH, as previous described (24). The enzyme activity was determined using an assay kit (Beyotime Institute of Biotechnology) according to the manufacturer's protocol. Briefly, the cells were treated with LDH release agent (which served as the maximum viability), and the medium containing the detached cells was collected and centrifuged. The supernatant was used for the assay of LDH activity. A spectrophotometer was used to measure the optical density (OD) value at $490 \mathrm{~nm}$. The percentage of damaged cells was calculated according to the

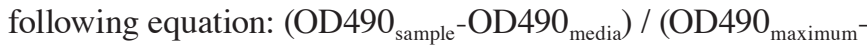
OD $490_{\text {media }}$ ) $x 100$, where OD490 ${ }_{\text {media }}$ was the OD of media without cells, and OD490 maximum $_{\text {was }}$ the OD of cells treated with $\mathrm{LDH}$ release agent.

Furthermore, a trypan blue staining assay was performed to confirm the results of the LDH assay. Following each treatment, cells were stained with $0.4 \%$ trypan blue (Beyotime Institute of Biotechnology) for $5 \mathrm{~min}$ at room temperature. Unstained cells were regarded as viable, and stained cells were regarded as dead. The total cell number and the number of trypan blue-positive cells were counted using a light microscope in a blinded manner. The percentage of surviving cells was calculated using the formula: Number of stained cells / number of total cells x100.

Statistical analysis. SPSS 15.0 software (SPSS, Inc., Chicago, IL, USA) was used to conduct the statistical analysis. Values are presented as the mean \pm standard error of the mean. Statistical comparisons between groups were performed using one-way analysis of variance followed by Tukey's post hoc test. $\mathrm{P}<0.05$ was considered to indicate a statistically significant difference.

\section{Results}

EMSA for $N F-\kappa B$ activity. NF- $\kappa \mathrm{B}$ DNA-binding activity in the cultured neurons was detected by EMSA. The results demonstrated that $\mathrm{NF}-\kappa \mathrm{B}$ activity was significantly higher at all post-trauma time points compared with that in the control group. Furthermore, following an initial peak at $1 \mathrm{~h}$, a distinct second peak of NF- $\kappa$ B activation was observed at $24 \mathrm{~h}$ in the neurons following the insult induced by transection (Fig. 1).

Protein levels of p65 and c-Rel in the nucleus. Western blotting was performed to detect the protein levels of p65 and c-Rel. The results reveal that the pattern of p65 expression in the nucleus was consistent with the activation of $N F-\kappa B$, and also presented double peaks. The first peak was at $1 \mathrm{~h}$ and the second was at $24 \mathrm{~h}$ (Fig. 2B). However, the c-Rel expression increased over time and was significantly increased compared with that in the control in the later stage (24-48 h) following traumatic neuronal injury, while no significant differences were detected from the control during the earlier period following transection injury (Fig. 2C).

Immunofluorescent labeling of p65 and c-Rel. Immunofluorescence analysis was performed to investigate the expression and distribution of the two main subunits of $\mathrm{NF}-\kappa \mathrm{B}$, namely p65 and c-Rel. This type of single cell analysis is advantageous when studying signal transduction as it helps to identify the cell types involved. Double labeling with antibodies against the neuron-specific NeuN protein and either 

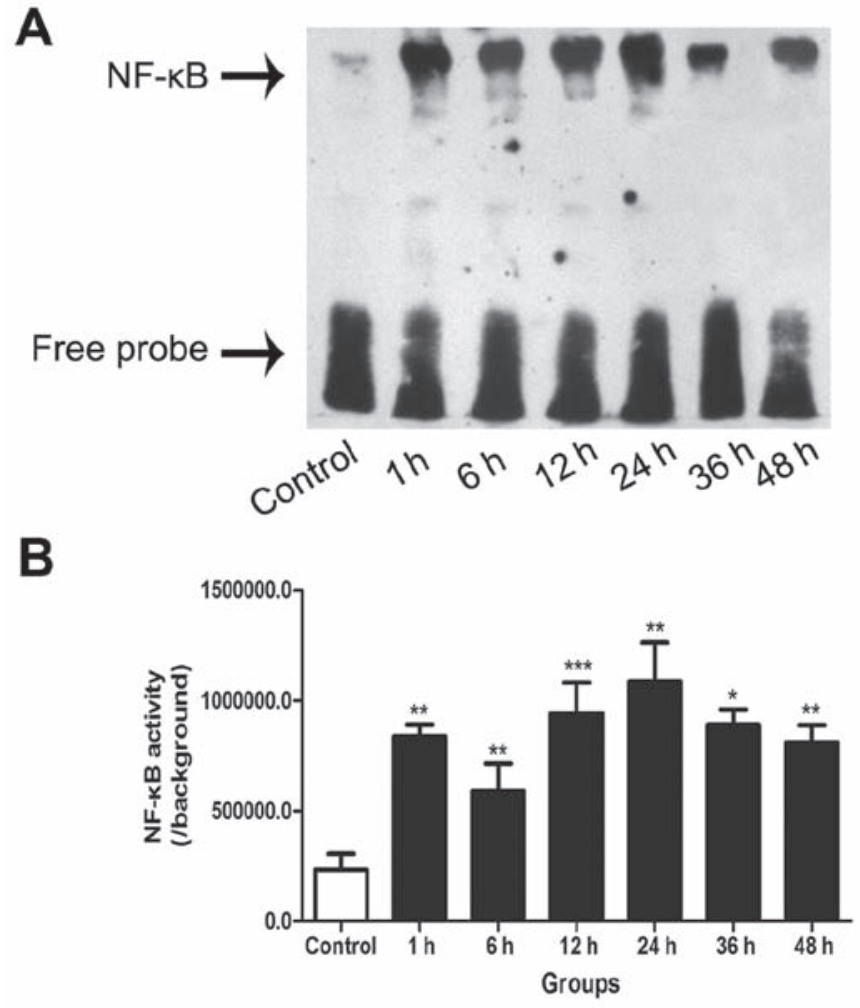

Figure 1. NF- $\mathrm{kB}$ DNA-binding activity in cultured neurons was determined by EMSA in the control group and at 1, 6, 12, 24, 36 and $48 \mathrm{~h}$ following transection. (A) EMSA results and (B) quantitative analysis reveal that $\mathrm{NF}-\kappa \mathrm{B}$ activity in the transection groups was significantly increased compared with that in the control group, presenting double peaks at 1 and $24 \mathrm{~h}$ post-injury, ${ }^{*} \mathrm{P}<0.05,{ }^{* *} \mathrm{P}<0.01$ and ${ }^{* * * *} \mathrm{P}<0.001$ vs. control group. Bars represent the mean \pm standard error of the mean ( $n=6$ per group). NF- $\kappa B$, nuclear factor- $\kappa \mathrm{B}$; EMSA, electrophoretic mobility shift assay.

p65 or c-Rel revealed colocalization in the neuronal cells. In the control groups, the neurons displayed staining of the two NF-kB subunits in the cytoplasm but weak or no staining in the nuclei (Fig. 3). However, in the 1 and $24 \mathrm{~h}$ groups, a marked increase of immunoreactivity for $\mathrm{p} 65$ in the nuclei was detected (Fig. 3). Increased nuclear staining for c-Rel was also observed in the $24 \mathrm{~h}$ groups (Fig. 3).

RT-qPCR for the detection of $I L-1 \beta, T N F-\alpha$, caspase- 3 and $B c l-2 m R N A$. In the neurons following transection injury, the expression of TNF- $\alpha$ mRNA increased and exhibited two peak phases at 6 and $24 \mathrm{~h}$ (Fig. 4A). The mRNA expression of another inflammatory mediator, IL-1 $\beta$ was significantly increased at 12 and 36 h (Fig. 4B). Furthermore, caspase-3 mRNA expression reached peak levels in the $1 \mathrm{~h}$ and 24 groups (Fig. 4C), accordant with the NF- $\kappa B$ activation pattern. The mRNA levels of Bcl-2 were also elevated at 1 and $24 \mathrm{~h}$, respectively (Fig. 4D).

LDH release detection and trypan blue staining. LDH quantification was used to evaluate the neuronal injury at different time-points following transection injury. LDH leakage was significantly increased in the scratched groups compared with the control groups (Fig. 5A). However, there was no significant further increase in LDH leakage during the late NF- $\mathrm{KB}$ activity peak, indicating that no sustained injury of the neurons occurred.

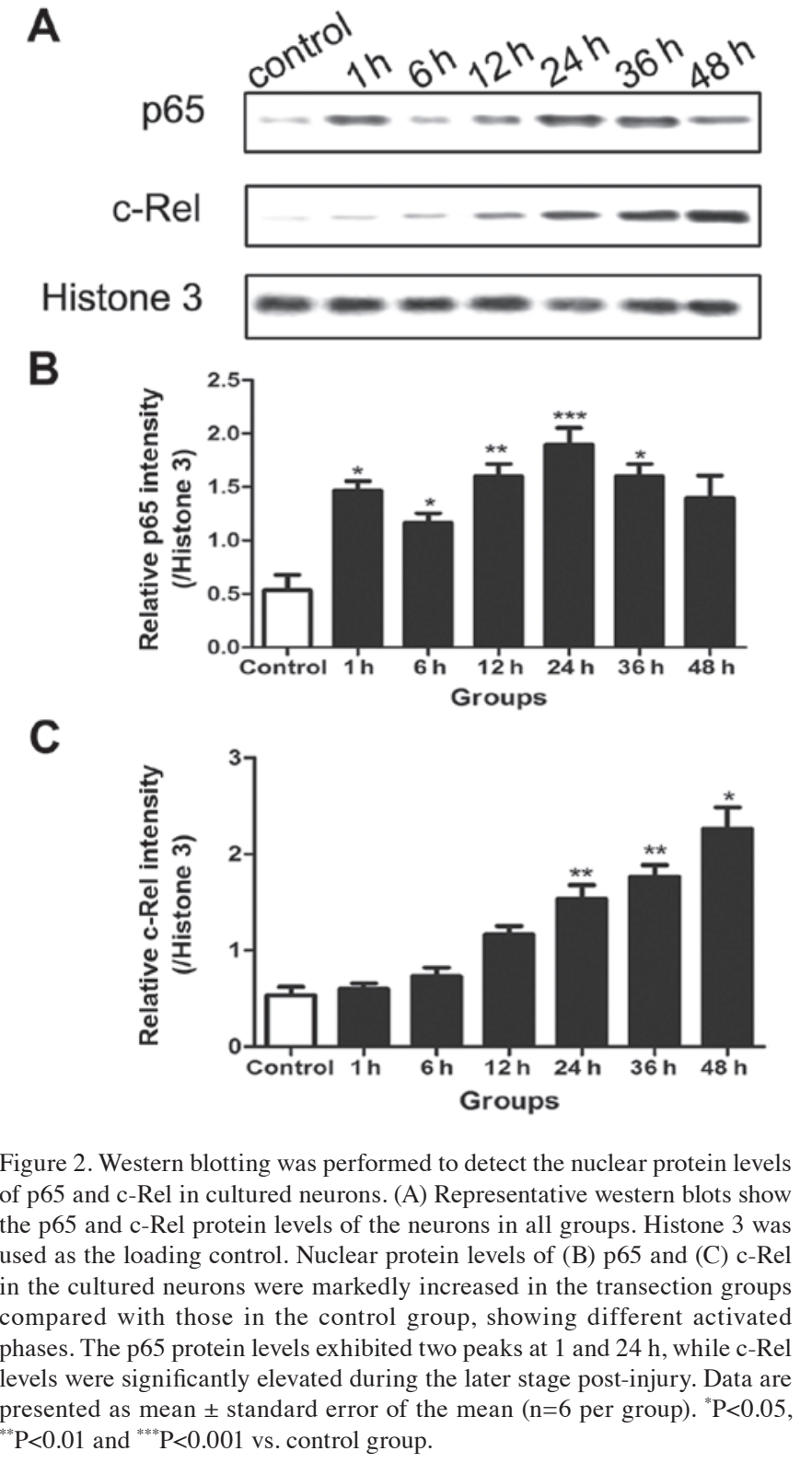

The trypan blue staining results indicated that the number of surviving neurons was significantly decreased during the early activation phase of NF- $\mathrm{KB}$, but no further marked reductions in cell survival were observed in the later phase (Fig. 5B).

\section{Discussion}

In the present study, it was demonstrated that biphasic activation of NF- $\kappa \mathrm{B}$ is induced in primary cultured neurons following transection injury, with an early peak of NF- $\mathrm{kB}$ activity at $1 \mathrm{~h}$ followed by a second late-phase peak at $24 \mathrm{~h}$. Furthermore, the two main subunits of NF-kB, p65 and c-Rel exhibited different changes. The alterations in the protein levels of p65 in the nucleus corresponded with the changes in NF- $\kappa \mathrm{B}$ activities, while the protein levels of the c-Rel subunit were particularly elevated during the late period; these observations were confirmed by immunofluorescence. The downstream gene transcriptions of NF- $\mathrm{\kappa B}$ presented similar biphasic changes following the NF- $\mathrm{kB}$ activation. These findings suggest for the 


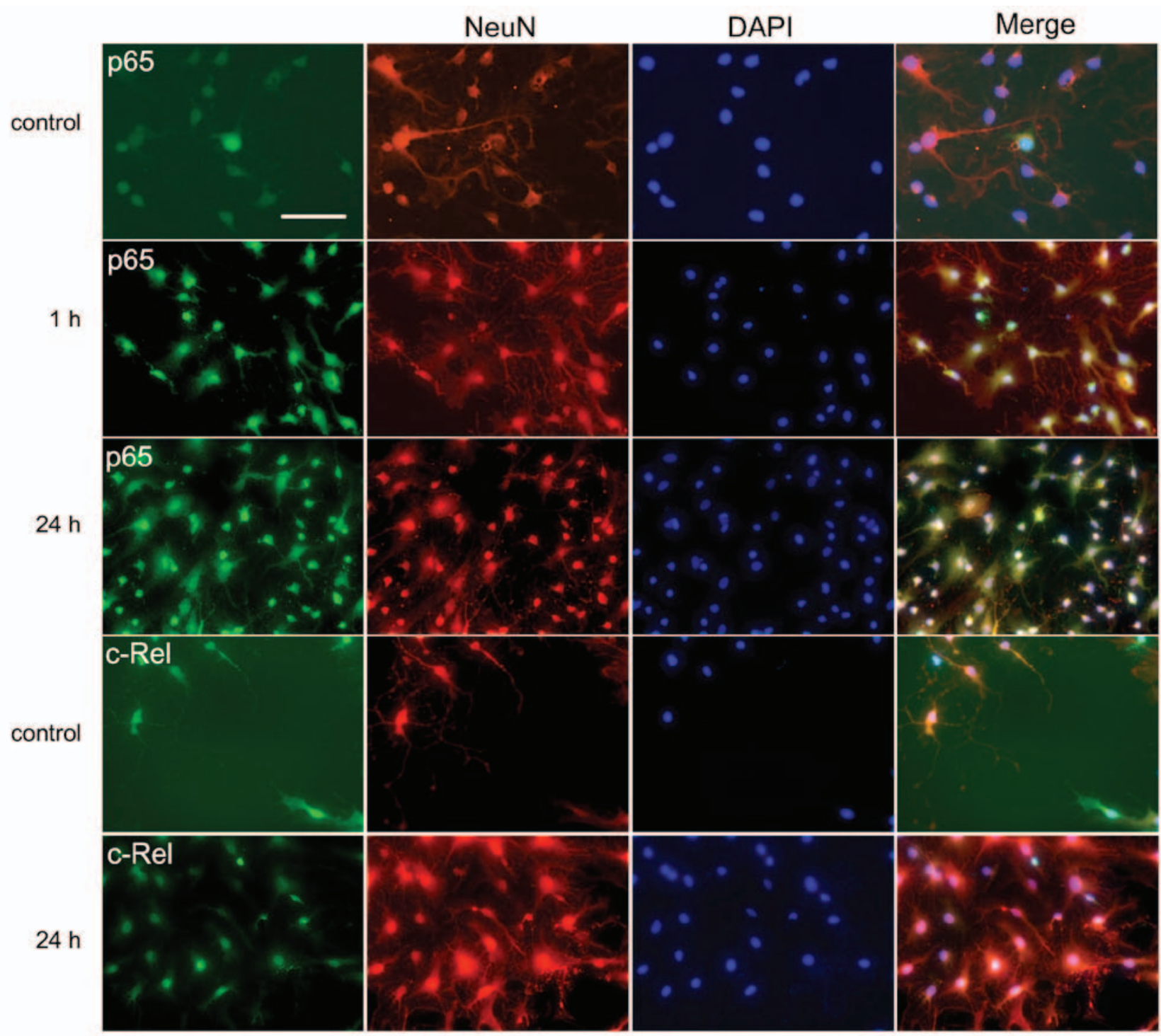

Figure 3. Representative photomicrographs of the fluorescent double staining of NeuN (red), p65 (green) or c-Rel (green). Nuclei were counterstained with DAPI (blue). Scale bar, $50 \mu \mathrm{m}$. The colocalization of NeuN with p65 or c-Rel was demonstrated. In the control groups, p65 and c-Rel displayed staining mostly in the cytoplasm but weak or no staining in the nuclei. In the 1 and $24 \mathrm{~h}$ groups, p65 accumulated in the nuclei, whereas c-Rel was observed to accumulate in the nuclei in the $24 \mathrm{~h}$ group. NeuN, neuronal nuclei.

first time, to the best of our knowledge, that biphasic activation of NF-kB may be induced following traumatic neuronal injury.

In the central nervous system, NF-kB is widely distributed in neurons, microglia, astrocytes and oligodendrocytes. In response to external stimuli, NF- $\mathrm{kB}$ is released from binding to its inhibitor, I $\mathrm{B}$, when the latter is degraded and the free NF- $\mathrm{kB}$ translocates to the nucleus where the transcription of downstream genes is activated (25). Numerous studies have demonstrated that the NF- $\mathrm{kB}$ pathway serves an essential role in the pathophysiological processes of various central system diseases, including TBI and subarachnoid hemorrhage. Among these studies, some have suggested a neuroprotective role of NF- $\mathrm{BB}(26,27)$, while others reported a neurodestructive role of NF-kB (28-30). Nijboer et al (17) described the biphasic activation of NF- $\mathrm{KB}$ in a hypoxic-ischemic brain damage model and suggested that NF- $\mathrm{KB}$ may serve different roles in neurons at different time-points, that is, during early brain injury and later brain repair. In addition, another study observed the biphasic expression of NF- $\mathrm{KB}$ in experimental models of subarachnoid hemorrhage (16). However, whether NF-кB activities present similar changes following TBI remains poorly understood. Previous studies by the present research team indicated that the biphasic activation of NF- $\mathrm{kB}$ occurs following TBI in rats (31). In the present study, a transection model of primary cultured neurons was employed in which to detect NF- $\mathrm{\kappa B}$ activities following neuronal damage in vitro. Notably, NF-kB exhibited two peaks of significantly increased activity at 1 and $24 \mathrm{~h}$ following transection. The expression of different subunits of NF- $\kappa \mathrm{B}$, namely p65 and c-Rel was further investigated in the present study. Previous studies have demonstrated that the activation of a distinct combination of $\mathrm{NF}-\mathrm{\kappa B}$ subunits may result in the differential regulation of target genes and the induction of diverse genetic programs that dictate the cell fate (32-34). Importantly, Pizzi et al (15) demonstrated opposing roles for the NF-kB/Rel factors $\mathrm{p} 65$ and $\mathrm{c}-\mathrm{Rel}$ in the modulation of neuron survival elicited by glutamate and IL-1 $1 \beta$. Previous studies have also suggested that numerous cerebral system diseases have different etiologies 
A

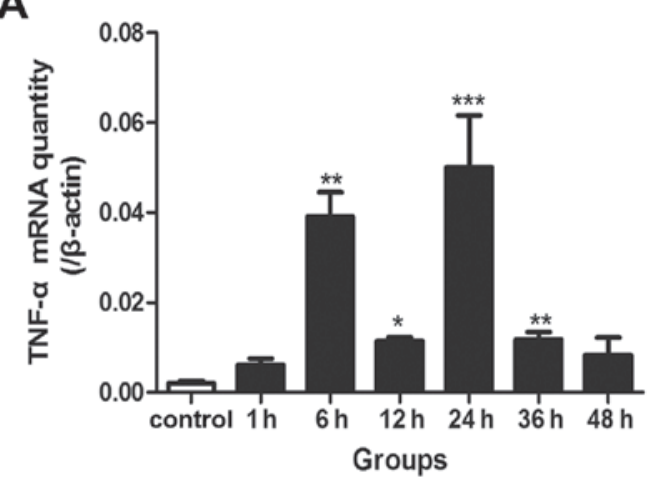

C

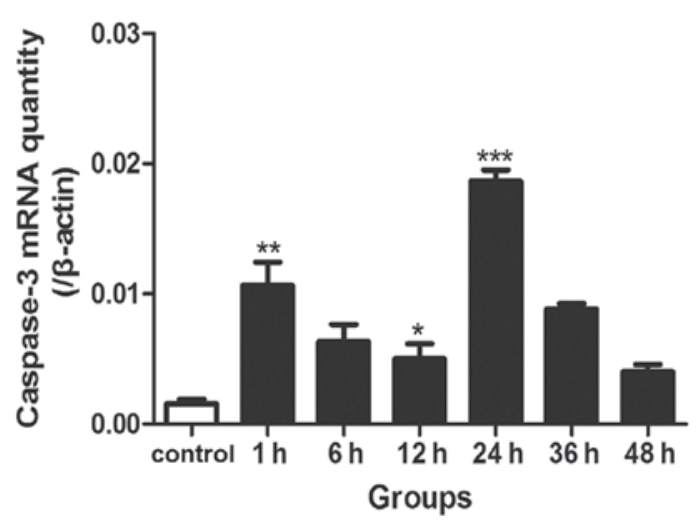

B

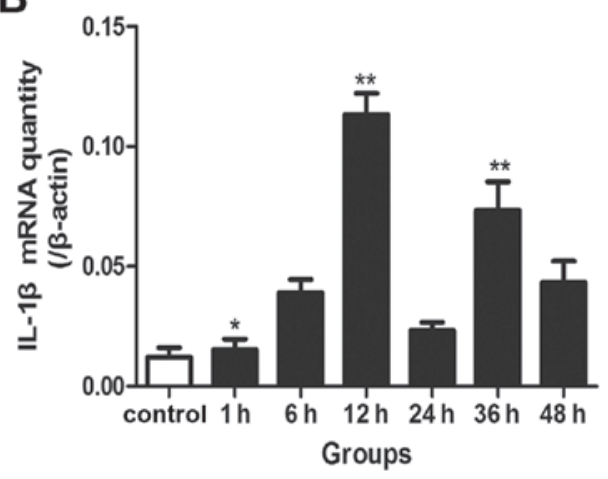

D

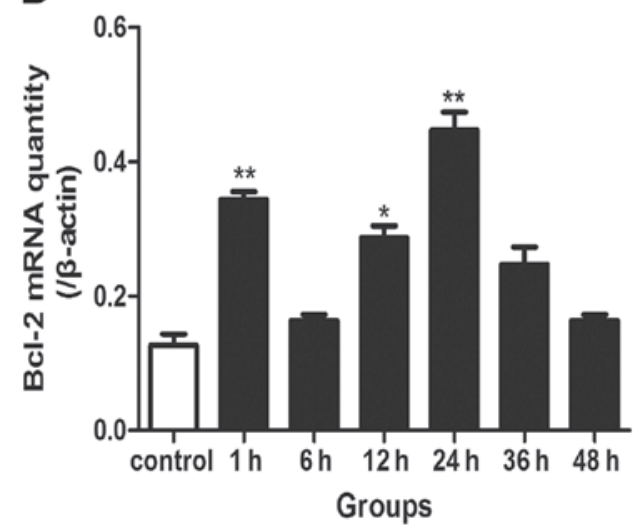

Figure 4. The mRNA levels of NF- $\mathrm{BB}$ downstream genes were detected by reverse transcription-quantitative polymerase chain reaction. (A) TNF- $\alpha$ mRNA expression was increased significantly in the 6 and $24 \mathrm{~h}$ groups, showing a biphasic increase. (B) IL-1 $\beta$ mRNA was markedly elevated in the 12 and $36 \mathrm{~h}$ groups. (C) Caspase- 3 mRNA expression also exhibited two peaks in the 1 and $24 \mathrm{~h}$ groups. (D) Bcl- 2 mRNA expression was markedly increased in the 1 and $24 \mathrm{~h}$ groups. ${ }^{*} \mathrm{P}<0.05,{ }^{* *} \mathrm{P}<0.01$ and ${ }^{* * * *} \mathrm{P}<0.001$ vs. control group. Bars represent the mean \pm standard error of the mean ( $\mathrm{n}=6$ per group). NF- $\mathrm{B}$, nuclear factor- $\kappa \mathrm{B}$; TNF- $\alpha$, tumor necrosis factor- $\alpha$; IL-1 $\beta$, interleukin-1 $\beta$; Bcl-2, B-cell lymphoma 2.

A

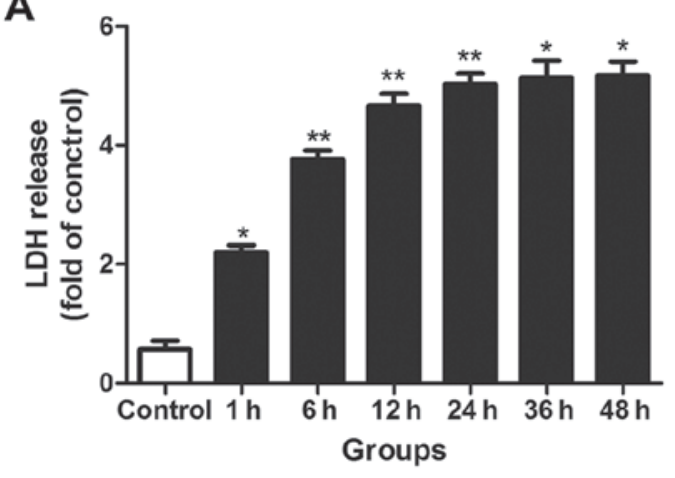

B

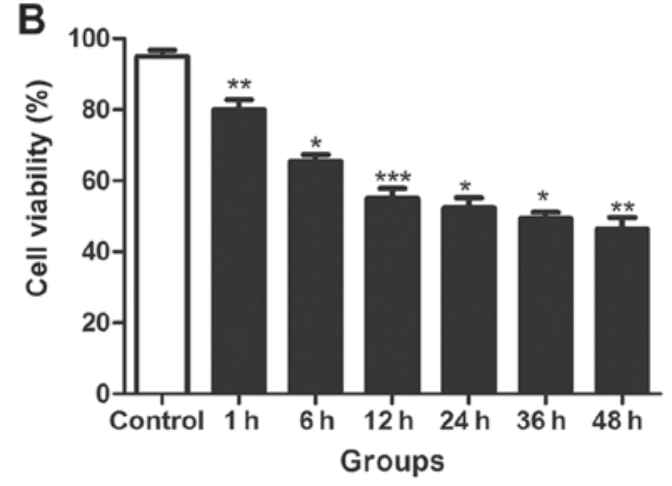

Figure 5. LDH release assay was performed for the assessment of neuronal injury. (A) Significant increases in LDH release were observed in all groups following transection injury compared with the control group. During the late stages, LDH release exhibited no marked further increase. (B) Trypan blue staining was performed to evaluate neuronal death. Following transection injury, the viability of the neurons initially decreased markedly while in the later stages, neuronal viability decreased only very slowly. ${ }^{*} \mathrm{P}<0.05,{ }^{* *} \mathrm{P}<0.01$ and ${ }^{* * *} \mathrm{P}<0.001$ vs. control group. Bars represent the mean \pm standard error of the mean ( $n=6$ per group). LDH, lactate dehydrogenase.

yet similar mechanisms (35). Based on these observations, the expression and distribution of $\mathrm{p} 65$ and c-Rel were detected in the present study to investigate their involvement in the physiological processes in neurons following transection injury. The results demonstrated that $\mathrm{p} 65$ and c-Rel exhibited different expression phases following neuronal damage, suggesting that these two different subunits may participate in different pathophysiological processes.
LDH leakage is considered to be associated with the disruption of cell membrane integrity, which may occur following the apoptotic or necrotic death of mature neurons (36). In the current study, LDH leakage exhibited a significant increase during the early peak in injured neurons but did not markedly increase further during the later phase. Similar results were observed with trypan blue staining. Thus, it may be inferred that the early peak in NF-kB activity promoted neuron death, 
while the late one did not significantly aggravate neuron damage, which may be beneficial for neuron survival.

The mRNA levels of target genes of $\mathrm{NF}-\kappa \mathrm{B}$ were further investigated in the present study. Previous studies have demonstrated that $\mathrm{NF}-\kappa \mathrm{B}$ is able to provide cell protection through upregulating the expression of anti-apoptotic factors such as $\mathrm{Bcl}-2$ (37). Bcl-2 binds to Bax and Bcl-2 antagonist (Bak) thereby preventing Bax/Bak pore formation in the mitochondrial membrane. In the current study, Bcl-2 mRNA expression altered in a similar manner to $\mathrm{NF}-\kappa \mathrm{B}$ activity. However, caspase-3, a crucial mediator of apoptosis for neurons, was also elevated following the peak $\mathrm{NF}-\kappa \mathrm{B}$ activation. The pro- and anti-apoptotic genes presented the same tendency to increase as $\mathrm{NF}-\kappa \mathrm{B}$ activity increased, which is confusing with regard to the neuronal fate. $\mathrm{NF}-\kappa \mathrm{B}$ activation has been described to promote brain damage via the induction of pro-inflammatory cytokines, including TNF- $\alpha$ and IL-1 $\beta$ (38). However, inflammatory cytokines may also provide a neuroprotection-like effect in certain conditions by promoting growth, repair, and ultimately, enhanced functional recovery $(39,40)$. In the present study, TNF- $\alpha$ and IL- $1 \beta$ displayed a biphasic expression pattern, leading to the hypothesis that TNF- $\alpha$ and IL-1 $\beta$ may provide protective effects in the later phase of traumatic neuronal injury. The reciprocal interaction between the proand anti-apoptotic signals regulated by $\mathrm{NF}-\kappa \mathrm{B}$ and its role in inflammatory cytokine production therefore complicate the prediction of the effect of $\mathrm{NF}-\kappa \mathrm{B}$ on neuronal injury. The exact mechanism requires further investigation in future studies. The present research team are carrying out additional investigations to discover the complex association between them.

In conclusion, the present study observed for the first time that biphasic activation of $\mathrm{NF}-\kappa \mathrm{B}$ occurred following traumatic neuronal injury in primary cultured neurons. In addition, the p65 and c-Rel subunits of NF- $\kappa \mathrm{B}$ were elevated during different phases post-injury. These preliminary data indicate that $\mathrm{NF}-\kappa \mathrm{B}$ may serve dual roles in the determination of neuronal fate. It is possible that the final decision of a neuron to live or die is made relatively late following injury However, the present study is a pilot study and has certain limitations, such as a lack of interventions and limited exploration of subunits. Future research aimed at NF- $\mathrm{BB}$-based interventions and therapeutic approaches to combat TBI are likely be valuable.

\section{Acknowledgements}

Not applicable.

\section{Funding}

The present study was supported by the National Natural Science Foundation, China (grant nos. 81171170 and 81371294) and the Nature Science Foundation of Jiangsu Province, China (grant no. BK2010459).

\section{Availability of data and materials}

The data and materials used or analyzed during the current study are available from the corresponding author on reasonable request.

\section{Authors' contributions}

$\mathrm{HZ}$ and $\mathrm{CH}$ designed the experiments. HZ, DZ, HY and HL carried out the experiments. $\mathrm{HZ}, \mathrm{ZZ}$ and $\mathrm{CZ}$ analyzed the experimental results. HZ, QC and ZY wrote the manuscript and critically revised it for important intellectual content. All authors read and approved the manuscript.

\section{Ethics approval and consent to participate}

Ethical approval was provided by the Medical Ethics Committee of Jinling Hospital. All surgical procedures were performed in accordance with guidelines of the Jinling Animal Care and Use Committee.

\section{Consent for publication}

Not applicable.

\section{Competing interests}

The authors declare that they have no competing interests.

\section{References}

1. Lescot T, Abdennour L, Degos V, Boch AL and Puybasset L: Management of severe traumatic brain injury. Presse Med 36: 1117-1126, 2007 (In French).

2. Chen T, Liu W, Chao X, Zhang L, Qu Y, Huo J and Fei Z: Salvianolic acid $\mathrm{B}$ attenuates brain damage and inflammation after traumatic brain injury in mice. Brain Res Bull 84: 163-168, 2011.

3. Greve MW and Zink BJ: Pathophysiology of traumatic brain injury. Mt Sinai J Med 76: 97-104, 2009.

4. Lu J, Goh SJ, Tng PY, Deng YY, Ling EA and Moochhala S: Systemic inflammatory response following acute traumatic brain injury. Front Biosci (Landmark Ed) 14: 3795-3813, 2009.

5. Bhakar AL, Tannis LL, Zeindler C, Russo MP, Jobin C, Park DS, MacPherson S and Barker PA: Constitutive nuclear factor-kappa B activity is required for central neuron survival. J Neurosci 22: 8466-8475, 2002.

6. Hayden MS and Ghosh S: Signaling to NF-kappaB. Genes Dev 18: 2195-2224, 2004.

7. Baldwin AS Jr: The NF-kappa B and I kappa B proteins: New discoveries and insights. Annu Rev Immunol 14: 649-683, 1996.

8. Mattson MP and Meffert MK: Roles for NF-kappaB in nerve cell survival, plasticity, and disease. Cell Death Differ 13: 852-860, 2006.

9. Shimada $\mathrm{M}$, Satoh $\mathrm{N}$ and Yokosawa $\mathrm{H}$ : Involvement of Rel/NF-kappaB in regulation of ascidian notochord formation. Dev Growth Differ 43: 145-154, 2001.

10. Zhang R, Xue YY, Lu SD, Wang Y, Zhang LM, Huang YL, Signore AP, Chen J and Sun FY: Bcl-2 enhances neurogenesis and inhibits apoptosis of newborn neurons in adult rat brain following a transient middle cerebral artery occlusion. Neurobiol Dis 24: 345-356, 2006.

11. Zhang Y, Liu J, Yao S, Li F, Xin L, Lai M, Bracchi-Ricard V, Xu H, Yen W, Meng W, et al: Nuclear factor kappa B signaling initiates early differentiation of neural stem cells. Stem Cells 30: 510-524, 2012.

12. Biscetti F, Ghirlanda G and Flex A: Therapeutic potential of high mobility group box-1 in ischemic injury and tissue regeneration. Curr Vasc Pharmacol 9: 677-681, 2011.

13. Basu S, Rajakaruna S and Menko AS: Insulin-like growth factor receptor-1 and nuclear factor $\kappa \mathrm{B}$ are crucial survival signals that regulate caspase-3-mediated lens epithelial cell differentiation initiation. J Biol Chem 287: 8384-8397, 2012.

14. Youssef S and Steinman L: At once harmful and beneficial: The dual properties of NF-kappaB. Nat Immunol 7: 901-902, 2006.

15. Pizzi M, Goffi F, Boroni F, Benarese M, Perkins SE, Liou HC and Spano P: Opposing roles for NF-kappa B/Rel factors p65 and $\mathrm{c}$-Rel in the modulation of neuron survival elicited by glutamate and interleukin-1beta. J Biol Chem 277: 20717-20723, 2002. 
16. You WC, Li W, Zhuang Z, Tang Y, Lu HC, Ji XJ, Shen W, Shi JX and Zhou ML: Biphasic activation of nuclear factor-kappa B in experimental models of subarachnoid hemorrhage in vivo and in vitro. Mediators Inflamm 2012: 786242, 2012.

17. Nijboer CH, Heijnen CJ, Groenendaal F, May MJ, van Bel F and Kavelaars A: A dual role of the NF-kappaB pathway in neonatal hypoxic-ischemic brain damage. Stroke 39: 2578-2586, 2008.

18. Chen T, Fei F, Jiang XF, Zhang L, Qu Y, Huo K and Fei Z: Down-regulation of Homerlb/c attenuates glutamate-mediated excitotoxicity through endoplasmic reticulum and mitochondria pathways in rat cortical neurons. Free Radic Biol Med 52: 208-217, 2012.

19. Zhao Y, Luo P, Guo Q, Li S, Zhang L, Zhao M, Xu H, Yang Y, Poon W and Fei Z: Interactions between SIRT1 and MAPK/ERK regulate neuronal apoptosis induced by traumatic brain injury in vitro and in vivo. Exp Neurol 237: 489-498, 2012.

20. Tecoma ES, Monyer H, Goldberg MP and Choi DW: Traumatic neuronal injury in vitro is attenuated by NMDA antagonists. Neuron 2: 1541-1545, 1989.

21. Zhou ML, Shi JX, Hang CH, Cheng HL, Qi XP, Mao L, Chen KF and Yin HX: Potential contribution of nuclear factor-kappaB to cerebral vasospasm after experimental subarachnoid hemorrhage in rabbits. J Cereb Blood Flow Metab 27: 1583-1592, 2007.

22. Rogers B, Yakopson V, Teng ZP, Guo Y and Regan RF: Heme oxygenase-2 knockout neurons are less vulnerable to hemoglobin toxicity. Free Radic Biol Med 35: 872-881, 2003.

23. Livak KJ and Schmittgen TD: Analysis of relative gene expression data using real-time quantitative PCR and the 2(-Delta Delta C(T)) Method. Methods 25: 402-408, 2001

24. Hatic H, Kane MJ, Saykally JN and Citron BA: Modulation of transcription factor Nrf2 in an in vitro model of traumatic brain injury. J Neurotrauma 29: 1188-1196, 2012.

25. Baeuerle PA and Baltimore D: I kappa B: A specific inhibitor of the NF-kappa B transcription factor. Science 242: 540-546, 1988.

26. Lezoualc'h F, Sagara Y, Holsboer F and Behl C: High constitutive NF-kappaB activity mediates resistance to oxidative stress in neuronal cells. J Neurosci 18: 3224-3232, 1998.

27. Mattson MP, Goodman Y,Luo H,Fu W and Furukawa K: Activation of NF-kappaB protects hippocampal neurons against oxidative stress-induced apoptosis: Evidence for induction of manganese superoxide dismutase and suppression of peroxynitrite production and protein tyrosine nitration. J Neurosci Res 49: 681-697, 1997.

28. Grilli M, Pizzi M, Memo M and Spano P: Neuroprotection by aspirin and sodium salicylate through blockade of NF-kappaB activation. Science 274: 1383-1385, 1996.
29. Clemens JA, Stephenson DT, Dixon EP, Smalstig EB, Mincy RE, Rash KS and Little SP: Global cerebral ischemia activates nuclear factor-kappa B prior to evidence of DNA fragmentation. Brain Res Mol Brain Res 48: 187-196, 1997.

30. Qin ZH, Wang Y, Nakai M and Chase TN: Nuclear factor-kappaB contributes to excitotoxin-induced apoptosis in rat striatum. Mol Pharmacol 53: 33-42, 1998.

31. Hu YC, Sun Q, Li W, Zhang DD, Ma B, Li S, Li WD, Zhou ML and Hang $\mathrm{CH}$ : Biphasic activation of nuclear factor kappa $\mathrm{B}$ and expression of p65 and c-Rel after traumatic brain injury in rats. Inflamm Res 63: 109-115, 2014.

32. Lin SC, Wortis HH and Stavnezer J: The ability of CD40L, but not lipopolysaccharide, to initiate immunoglobulin switching to immunoglobulin G1 is explained by differential induction of NF-kappaB/Rel proteins. Mol Cell Biol 18: 5523-5532, 1998.

33. Perkins ND: Achieving transcriptional specificity with NF-kappaB. Int J Biochem Cell Biol 29: 1433-1448, 1997.

34. Roshak AK, Jackson JR, McGough K, Chabot-Fletcher M, Mochan E and Marshall LA: Manipulation of distinct NFkappaB proteins alters interleukin-1beta-induced human rheumatoid synovial fibroblast prostaglandin E2 formation. J Biol Chem 271: 31496-31501, 1996.

35. Leker RR and Shohami E: Cerebral ischemia and trauma-different etiologies yet similar mechanisms: Neuroprotective opportunities. Brain Res Brain Res Rev 39: 55-73, 2002.

36. Xu J, Wang H, Ding K, Zhang L, Wang C, Li T, Wei W and $\mathrm{Lu} \mathrm{X}$ : Luteolin provides neuroprotection in models of traumatic brain injury via the Nrf2-ARE pathway. Free Radic Biol Med 71: 186-195, 2014.

37. Kuwana T and Newmeyer DD: Bcl-2-family proteins and the role of mitochondria in apoptosis. Curr Opin Cell Biol 15: 691-699, 2003.

38. Mattson MP and Camandola S: NF-kappaB in neuronal plasticity and neurodegenerative disorders. J Clin Invest 107: 247-254, 2001.

39. Cederberg D and Siesjö P: What has inflammation to do with traumatic brain injury? Childs Nerv Syst 26: 221-226, 2010.

40. Barone FC and Feuerstein GZ: Inflammatory mediators and stroke: New opportunities for novel therapeutics. J Cereb Blood Flow Metab 19: 819-834, 1999.

This work is licensed under a Creative Commons Attribution-NonCommercial-NoDerivatives 4.0 International (CC BY-NC-ND 4.0) License. 